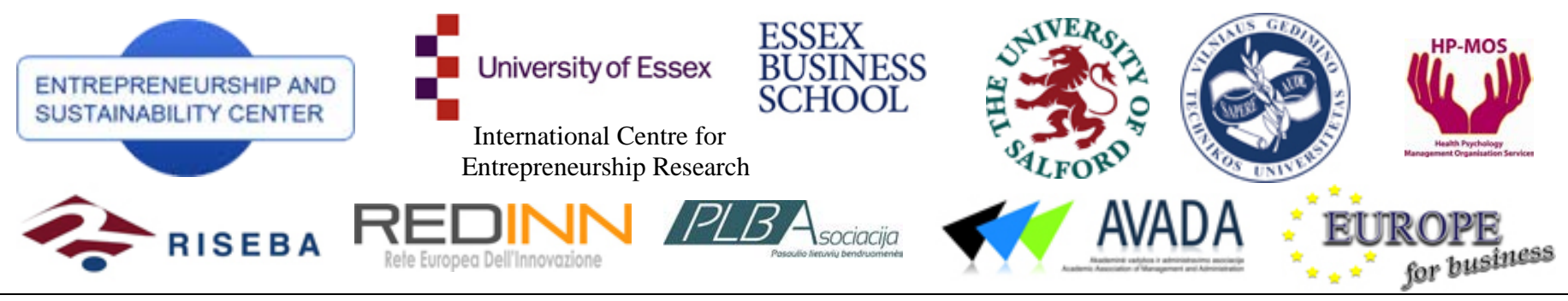

ENTREPRENEURSHIP AND SUSTAINABILITY ISSUES

ISSN 2345-0282 (online) http://jssidoi.org/jesi/

\title{
BUSINESS MODEL STRATEGIES: FLEXIBILITY TRADE IN LOW VOLTAGE DISTRIBUTION NETWORKS ${ }^{1}$
}

\author{
Patrick Lynch¹, Jamie Power1, Richard Hickey \& Thomas Messrevey² \\ ${ }^{1}$ RIKON-Waterford Institute of Technology, Waterford, Ireland \\ ${ }^{2}$ R2M Solution, Pavia, Italy \\ E-mail to Corresponding Author: ${ }^{1}$ plynch@wit.ie
}

Received 29 September 2016; accepted 16 November 2016

\begin{abstract}
Empowered by information and communication technologies (ICT) analytics and smart technologies, the energy model landscape is changing with flexibility at the core of a new energy market design. In particular, multi-sided platforms (MSPs) has gained prominent attention as a business model that creates value by enabling direct interactions between several distinct groups of actors who need each other in order to deliver products to their customers. However, as MSPs are less familiar within the energy market, there has been little investigation in modelling this emerging and dynamic ecosystem. Utilising the business modelling methodology of value network analysis and the key informant technique, value flows were modelled within the context of a MSP to understand the creation, delivery and capture of value in a network of interdependent relationship, its networked position and the stakeholder interactions required for delivery of local flexibility. Supported by this analysis, this paper focuses on the LV area of the smart grid, and presents the Local Flexibility Market (LFM) as a Multi-Sided Plarform. In comparison to the traditional utility model, the complexity of this recharacterization of the industry ecosystem is significant. While it presents new opportunities for incumbent energy providers to collaborate and develop new products, the proposed LFM market design will also dramatically reshape the value model of the industry.
\end{abstract}

Keywords: Smartgrid; Low Voltage Grid; Flexibility Management; Local Flexibility Market; Local Flexibility Aggregator; Prosumer; Local Energy Community; Multi-Sided Business Models

Reference to this paper should be made as follows: Lynch, P., Power, J., Hickey, R., Messervey, T. 2017. Business model strategies: Flexibility trade in emerging low voltage distribution networks, Entrepreneurship and Sustainability Issues, 380-391. http://dx.doi.org/10.9770/jesi.2017.4.3S(12)

\footnotetext{
${ }^{1}$ This research was supported by the project Mas ${ }^{2}$ tering (www.mas2tering.com), which has received funding from the European Union's FP7 research and innovation programme under the grant agreement No 619682.
}

The article reflects the views only of the authors, and the Commission cannot be held responsible for any use which may be made of the information contained therein. The information in this document is provided as is and no guarantee or warranty is given that the information is fit for any particular purpose. The user thereof uses the information at its sole risk and liability 


\section{Introduction}

Developing infrastructures, technologies and supporting business models to unlock energy market flexibility is currently one of the core questions discussed in various key energy policy circles in Europe (European Commission 2015 a; b; EC Europa 2015). In an environment of increased deregulation, competition and collaboration, achieving a demand-responsive smart-grid depends not only on the intersection between ICT and energy infrastructure but equally on sustainable business models and stakeholder collaboration (Mourshed, et al., 2015). The technologies, methods and aspects surrounding the smart grid are disruptive innovations that present both challenges and opportunities to utility business models and the actors involved (Lynch et al., 2016a; b; AlaJuusela et al., 2014). For the power industry, business as normal will likely not be possible and those maintaining traditional practices will likely fall to competitive pressures. Driven by both technology developments and policy targets, Europe's energy system is and will continue to undergo significant transformations, with flexibility as a cornerstone of emerging energy market design. "We are transitioning away from a power system in which controllable power stations follow electricity demand, to an overall efficient power system where flexible producers, flexible consumers and storage systems respond to increasing intermittent supply of wind and solar power" (BNE, 2015: 1). Within this vein of transformation, increasing focus is being placed at exploring the local level markets. Decentralised energy (DE) is energy generated at or near the point of use and involves offers buildings (including both domestic and residential) doubling up as power stations via their usage of generating technologies such as solar panels, wind turbines or cogeneration units. The growing interest in local energy communities is further fuelled by the increasing adoption of both distributed energy resources (DERs), and residential Internet of Things (IoT) devices.

These advancements are paving the way for paradigm shifts in the energy generation/distribution system. Indeed, moving from a unidirectional electricity grid system that delivers energy from centralized power plants to customers through transmission and distribution lines represents a disruptive shift (Wainsteina \& Bumpus, 2016). Such transformations in energy systems, necessitates the need for exploring the role of innovative business models and adapting, and in some cases creating new stakeholder roles, to realise the opportunities available associated with flexibility in local market contexts from the context of Prosumers ("pro" in prosumer comes from production) and aggregators (Steinheimer and Ulrich, 2012; Rathnayaka, et al., 2011). In comparison to the traditional utility model, the complexity of this recharacterization of the industry ecosystem and business model is significant. To date, energy market actors have primarily focused on technology advancement within the smart grid which is within their comfort zone, however, this recharacterization will also require a call to action to engage in business model transformation which is new to most (Valocchi et al., 2010)

In this fashion, the main contribution of this paper is that from an ecosystem perspective, the business modelling methodology of value network analysis (VNA) was utilised (Peppard and Rylander, 2006) to develop a multisided business model (MSP) for a local flexibility aggregator to facilitate flexibility management between Suppliers, Wholesale Market Aggregators (WMAs), Distribution System Operators (DSOs), Consumers and Prosumers in the Low Voltage area of the grid. This paper argues that empowered by ICT, analytics and smart technologies, the emergence of the Prosumer as an active participant in the energy value chain will herald the era of multi-sided platforms (MSPs) which fundamentally changes the energy model landscape with flexibility at the core of a new energy market design. The rest of the paper is structured as follows. In the next section we discuss the business model shift to MSPs. Section 3 defines the Local Flexibility Market (LFM) and the actor's roles. 


\section{ENTREPRENEURSHIP AND SUSTAINABILITY ISSUES \\ The International Journal}

ISSN 2345-0282 (online) http://jssidoi.org/jesi/

2017 Volume 4 Number 3 (March)

Next we present our intial findings around the conceptualsing the LFM as a MSP. Finally, Section 5 states the concluding remarks and discusses some directions for future works.

\section{Business Model Shift}

The traditional power grid was designed only to carry energy from few central generation points to the final users. Today however, the power grid is facing a series of new demands (Mourshed, et al., 2015). Following the adoption by EU countries of the Directives for the reduction of $\mathrm{CO}_{2}$ emissions, the last 10-15 years have seen the increasing penetration of Renewable Energy Resources (RES) on the grid. Typically located at the Medium Voltage (MV) and Low Voltage (LV) levels, these intermittent and fluctuating distributed energy resources (DERs) require management to maintain grid stability and balance. The grid also continues to electrify. More users have higher demand profiles. Especially in urban areas, increasing grid capacity and avoiding grid congestion is a challenge. This will continue to worsen with the welcome increased penetration of electric vehicles although as storage systems their batteries can also provide solutions (Dupont et al., 2012). More and more, there is the need to manage and plan grid operations at the low voltage level where Consumers, Prosumers, Suppliers, WMA and DSOs will need to act and collaborate in new ways (BNE, 2015).

Converging evidence indicates that there is a real opportunity to resolve or mitigate some of the current challenges through the harnessing information and communication technologies (ICT), analytics, control strategies and smart devices for automating changes in how and when consumers consume, generate or store electricity (Euopean Commission, 2015a). When Consumers or Prosumers agree to change their planned consumption profile, this is called flexibility and the consequent shifting of loads can provide one tool to manage network capacity, congestion, and to achieve balance at local levels. If homes can individually and collectively level their demand load profile, then the generation, distribution and storage of electricity at the LV level (and indirectly at higher voltages) can be optimized (Lennard et al., 2015). Indeed, the increasing rate of intelligent domestic devices provides a real impetus for a smarter distribution network by creating a novel market energy model to maximise the advantages of DERs through smarter coordination of a prosumer community and DERs to provide more flexibility at the LV level. Smart consumers and prosumers are defined as those that use demand response to shift their flexible loads. Prosumer communities imply a collective force that would theoretically influence, and be influenced by the local energy market (Lynch et al., 2016a). Local flexibility is at the cornerstone of this new emerging energy market design (Rathnayaka, et al., 2011).

Bringing this opportunity to a reality, the formation of prosumer communities implies that they should have an intermediary to help manage DG (Distributed Generation) and DS (Distributed Storage) with regards to the injection of unused capacity to the LV-grid. A new role of a flexibility manager (Hagui, 2015) or aggregator (Valocchi et al., 2010; 2012) is foreseen in the energy value chain to act as an intermediator and facilitating agent between prosumers and traditional market players. The role being developed is one that combines the main aspects of flexibility management (Rochet, 2003) and aggregation (Ondrus, 2015) labeled the Local Flexibility Aggregator (LFA). The LFA represents a community of prosumers who through their own smart technologies will also become an integral part of the value chain as providers of flexibility. DSOs will be able to buy flexibility from LFAs to locally deal with congestions and increase grid performances and reliability (Lynch et al., 2016a).

In comparison to the traditional utility model (see Richter, 2012), the complexity of this recharacterization of the industry ecosystem is significant. While it presents new opportunities for incumbent energy providers to collaborate and develop new products and services, it will also dramatically reshape the value model of the industry as a whole and the value propositions required by the market (Wainsteina \& Bumpus, 2016). As energy, information and revenue flows can happen in various combinations, the nature of value has changed as there are far more types of reciprocal value and combinations of actor exchanges to deliver value. Moreover, as new types 


\section{The International Journal}

ENTREPRENEURSHIP AND SUSTAINABILITY ISSUES

ISSN 2345-0282 (online) http://jssidoi.org/jesi/

2017 Volume 4 Number 3 (March)

of reciprocal value will be generated, new value added businesses and services and new participants to the ecosystem that traditionally would not have been directly involved in the industry will emerge (Mourshed, et al., 2015). Consequently, the value capture opportunities available to the ecosystem participants will continuously increase, as will the complexity of the business models to capture and exploit that business value opportunity such as "platform-based business models" that services interdependent customer segments in an ecosystem concept (Hagiu, 2014). In particular, multi-sided platform (MSP) has gained prominent attention (Ondrus, 2015) as a business model that creates value by enabling direct interactions between several distinct groups of actors who need each other in order to deliver goods or services to their customers (Rochet, 2003). The real challenge of understanding such an emerging and dynamic complex business platform is to map out the flexibility business model opportunities that will take advantage of the new network-enabled capabilities that will allow companies to reap as much of the ecosystems' new value (Rochet, 2003; EURELECTRIC, 2011). However, there has been very little investigation in modelling this dynamic ecosystem beyond viewing business model value creation from the perspective of an individual actor which is not very effective when trying to ignite network based business models. It is the network of collaborative relationships that provides the key to understanding and realizing the business model opportunities within the ecosystem concept associated with flexibility in local market context (Steinheimer and Ulrich T, 2012; Rathnayaka, et al., 2011).

\section{Conceputalising the Local Flexibility Market as a Multi-Sided Business Platform (LFM)}

On an individual level, flexibility is "the modification of generation injection and/or consumption patterns in reaction to an external signal (price signal or activation) in order to provide a service within the energy system" (EURELECTRIC, 2014: 5). The parameters used to characterize flexibility in electricity include: the amount of power modulation, the duration, the rate of charge, the response time, and the location. Emerging in EU are technologies that allow for a two-way exchange between consumers and their energy supplier. Prosumers can be highly active in balancing the supply and demand of electricity as entrepreneurs, by storing electricity through electric car batteries or other storage facilities and providing electricity generated from renewable energy sources (RES), such as solar panels, or micro CHPs. Flexibility can be derived from various types of Active Demand and Supply (ADS) from small commercial and residential Prosumers, representing all the energy-consuming or producing appliances that have the ability to shift, increase, or decrease their energy consumption or production (programmability, automation, etc.). Smart consumers and smart prosumers are providers of flexibility. In a smart grid context each end user will use flexibility provided by his own smart technologies to reduce the costs associated with the energy bill of his house. According to Lynch et al. (2016a) the specific set of smart technologies end users will use flexibility to self-consume, move loads when cost of electricity is lower or for more complex management strategies. In most cases the reduction of the energy bill will be the first driver for consumers to become prosumers. However, besides using it in the house, prosumers can decide to offer their flexibility as a product to other actors.

Customers of flexibility acquired from residential and commercial sources include other Prosumers in the local community, the DSO that distributes energy to that local community and actors in the upstream value chain which may include other DSOs, aggregators of aggregators, balance responsible parties or TSOs. In simplified terms and as illustrated in Figure 1, depicted in the right proportion of the dotted line, the classical energy system market model involves the reliable and universal sale of energy at reasonable prices by utilities to consumers. Information flows (billing information from utilities to consumers) and revenue flows (from consumers to utilities) are unidirectional and the consumer plays a passive role (Lynch et al., 2016a). This 'one-sided' market model is called the "Utility" business model and has been largely unchanged over the last century.

The unbundling of energy markets and emergence of renewable energy technologies have begun to change the energy market model landscape (Dupont et al., 2012). The realization of the smart grid and emergence of a flexibility market will change it even more (Valocchi et al., 2010). This is depicted in the left portion of the dotted 
lines in Figure 1 which shows our conceptualization of a Local Flexibility Market model (LFM) where a LFA is between the consumer/prosumer and the upstream energy system actors (Lynch et al., 2016a). In comparison to the classical utility model, the complexity of the ecosystem is significant. Moving from a passive recipient of energy, within our conceptualsaion of the LFM, the Prosumer will now become an empowered and integral value chain participant offering flexibility (IEA-RETD, 2014). In a smart grid context each end user will use flexibility provided by his own smart technologies to reduce the costs associated with the energy bill of his house. According to the specific set of smart technologies end users will use flexibility to self-consume, move loads when cost of electricity is lower or for more complex management strategies (Rathnayaka, et al., 2011). In most cases the reduction of the energy bill will be the first driver for consumers to become prosumers. However, besides using it in the house, prosumers can decide to offer their flexibility as a product to other actors. In this sense, prosumers belonging to the community will be able to trade flexibility with each other in order to minimize the individual costs associated to their energy bill. One end user will not only rely on the flexibility provided by its own smart technologies, but will also be able to buy the flexibility provided by the other end users of the same community and globally reduce its bill. In addition, it will be possible to use flexibility in an aggregated - but still local - form to cope with local congestion problems (EURELECTRIC, 2011).

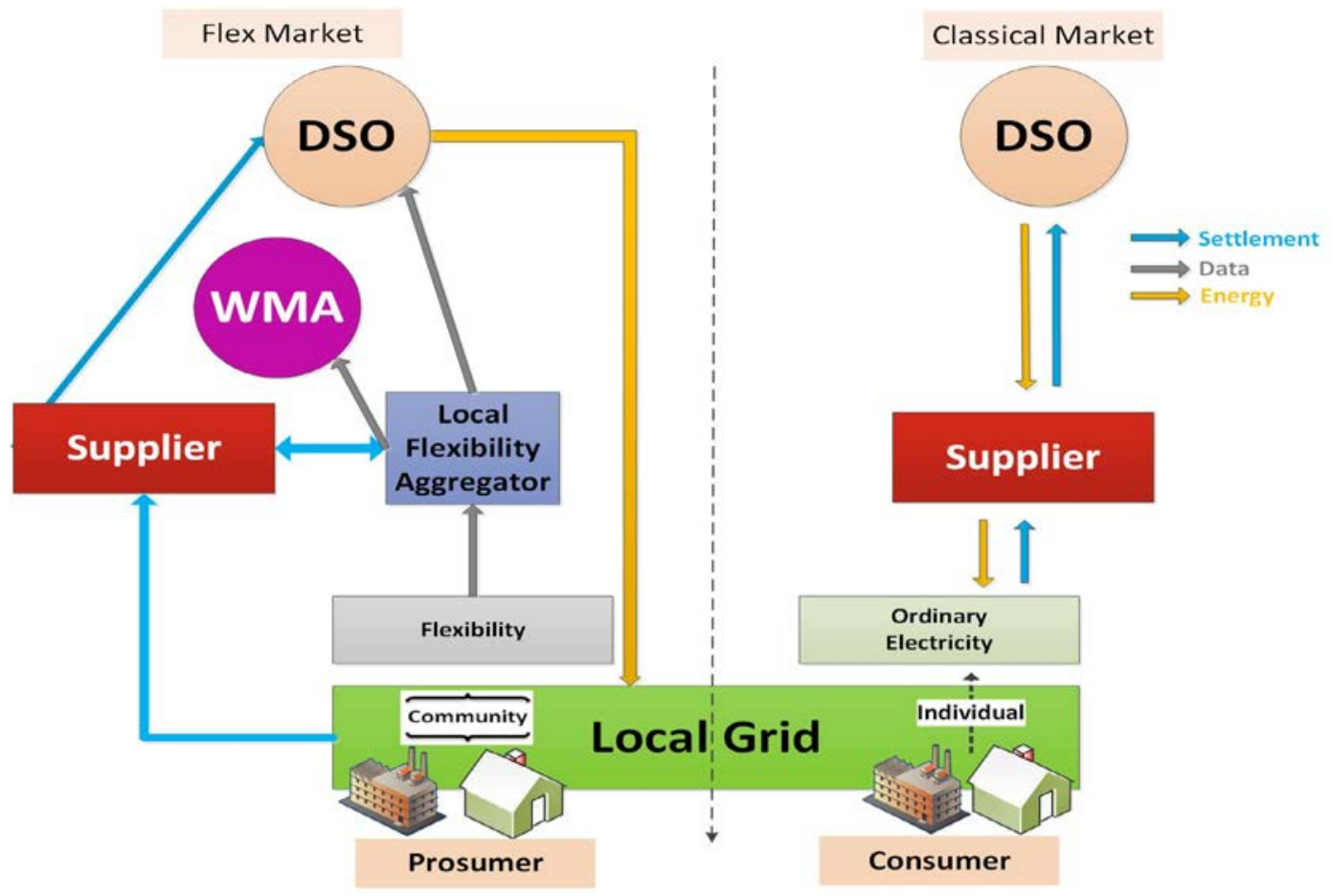

Figure 1. The Structure of the Local Flexible Market (LFM)

The LFA is responsible for acquiring flexibility from Prosumers, aggregating it into a portfolio, creating services that draw on the accumulated flexibility, and offering these flexibility services to the other market participants such as the WMA, DSO and other LFAs. Local flexibility is at the cornerstone of this new energy market design and is the added value of the proposed Local Flexible Market. The argument being proposed is that the centralised management of flexibility by the WMA is not always effective for congestion and capacity management and that local optimization of flexibility provided by the LFA ensures that flexibility is first used for in-home optimization; second traded at local level and; third aggregated for wholesale markets. For the DSO that provides 


\section{The International Journal}

ENTREPRENEURSHIP AND SUSTAINABILITY ISSUES

ISSN 2345-0282 (online) http://jssidoi.org/jesi/

2017 Volume 4 Number 3 (March)

services to a LEC, it is possible to use flexibility in an aggregated - but still local - form to cope with local congestion problems and capacity requirements. The DSO benefits from the local flexibility market in two ways. First, a more efficient and reliable distribution of electricity is possible because better balancing and predictability is attained at the local level. Second, investments to increase the capacity of the network can either be delayed or potentially avoided.

The problem with the evolution to the LFM proposed is that it is a grid of the future and the structure of the market place is uncertain. It will see the integration of the current market-based energy system and its players with new services and roles. These are required to unleash the added value provided by local flexibility, as described above. Table I presents a description of the actor roles and objectives in the LFM. There are additional actors in the ecosystem not depicted. These include telecom data services, security services and ancillary service providers. Key aspects when designing solutions for enabling flexibility management in the distribution network is that different actors and stakeholders will have different individual objectives that the system should optimize in order to guarantee their participation and interest to the proposed flexibility programs (Table 1).

TABLE 1. ACTOR ROLES \& OBJECTIVES

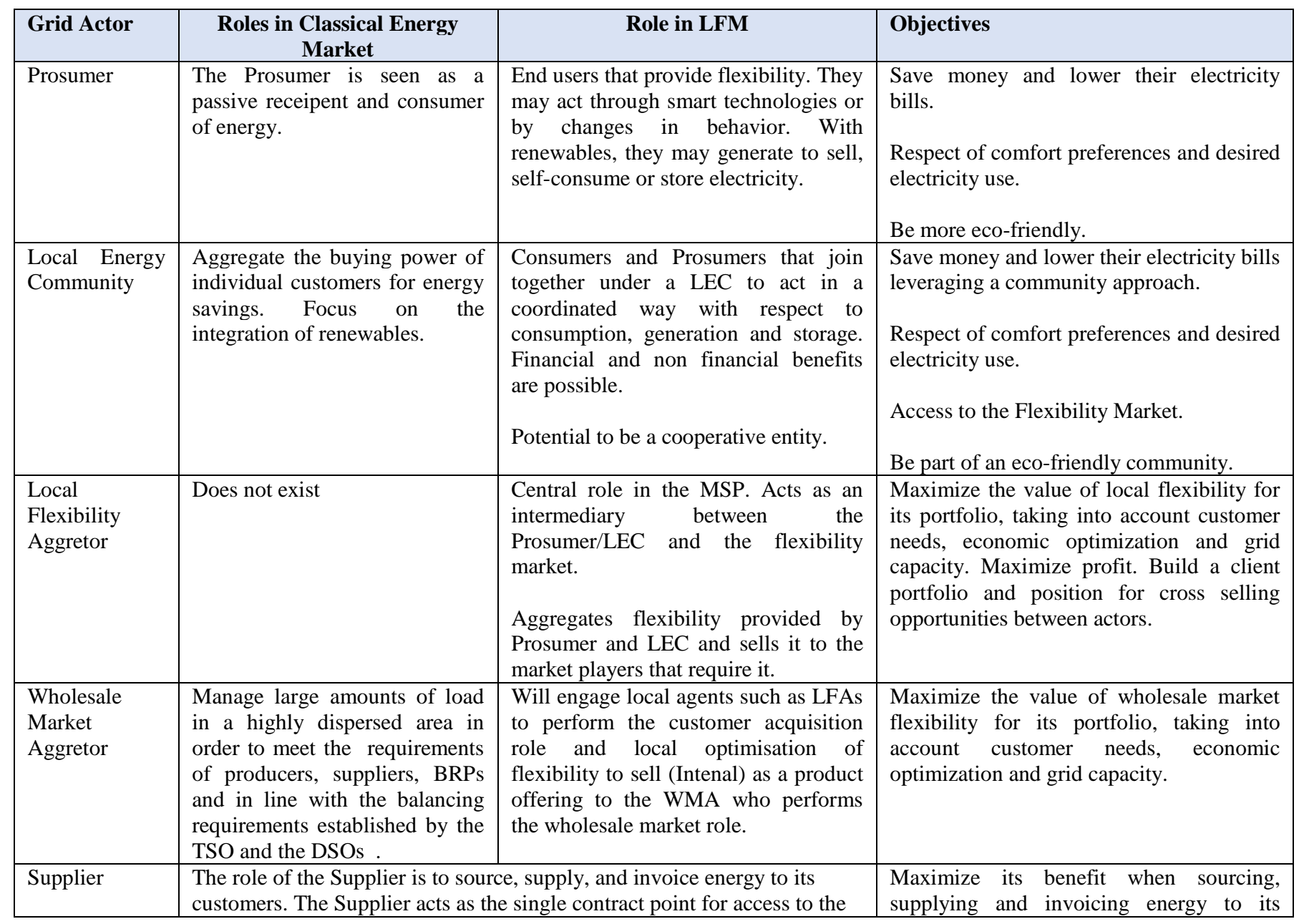




\begin{tabular}{|l|l|l|l|}
\hline & electricity market. & customers. \\
\hline DSO & $\begin{array}{l}\text { Distributes electricity at MV } \\
\text { and LV levels and ensures } \\
\text { quality of supply while } \\
\text { maintaining grid stability. }\end{array}$ & $\begin{array}{l}\text { LFA for congestion management and } \\
\text { voltage control. }\end{array}$ & $\begin{array}{l}\text { Use LV flexibility as a tool to reduce grid } \\
\text { congestion, further ensure the security of } \\
\text { supply and improve network capacity } \\
\text { planning. }\end{array}$ \\
\hline
\end{tabular}

\section{Conceputalising the Local Flexibility Market as a Multi-Sided Business Platform (LFM)}

Many platforms are single-sided platforms, with a seller at one end and a buyer at the other and, often, intermediaries (distributors) between them that transfer the product from buyer to seller without changing it substantively. The electric power network has historically operated as a single-sided platform. However, within the LFM model presented, the LFA clearly holds the central position and provides the link between the supply of Prosumers flexibility on one side and demand for flexibility by the market players on the other side. From a business and market modelling perspective this type of market design is referred to as a two-sided or multi-sided business market (Hagiu, 2014). In essence, LFM should be viewed from a Multi-Sided Platforms (MSPs) perspective because it brings together different sets of actors who might otherwise not get the chance to engage with each other. Flows of interactions can travel from one side of the market model to the other and in a multidirectional fashion

Lynch et al., (2016c) presents a conceptualisation of the Local Flexibility Market as a Multi-Sided Platform (LFM) (see Figure 2). Table II presents a synthesised explanation of the interactions between the various stakeholders across a number of interaction flows.

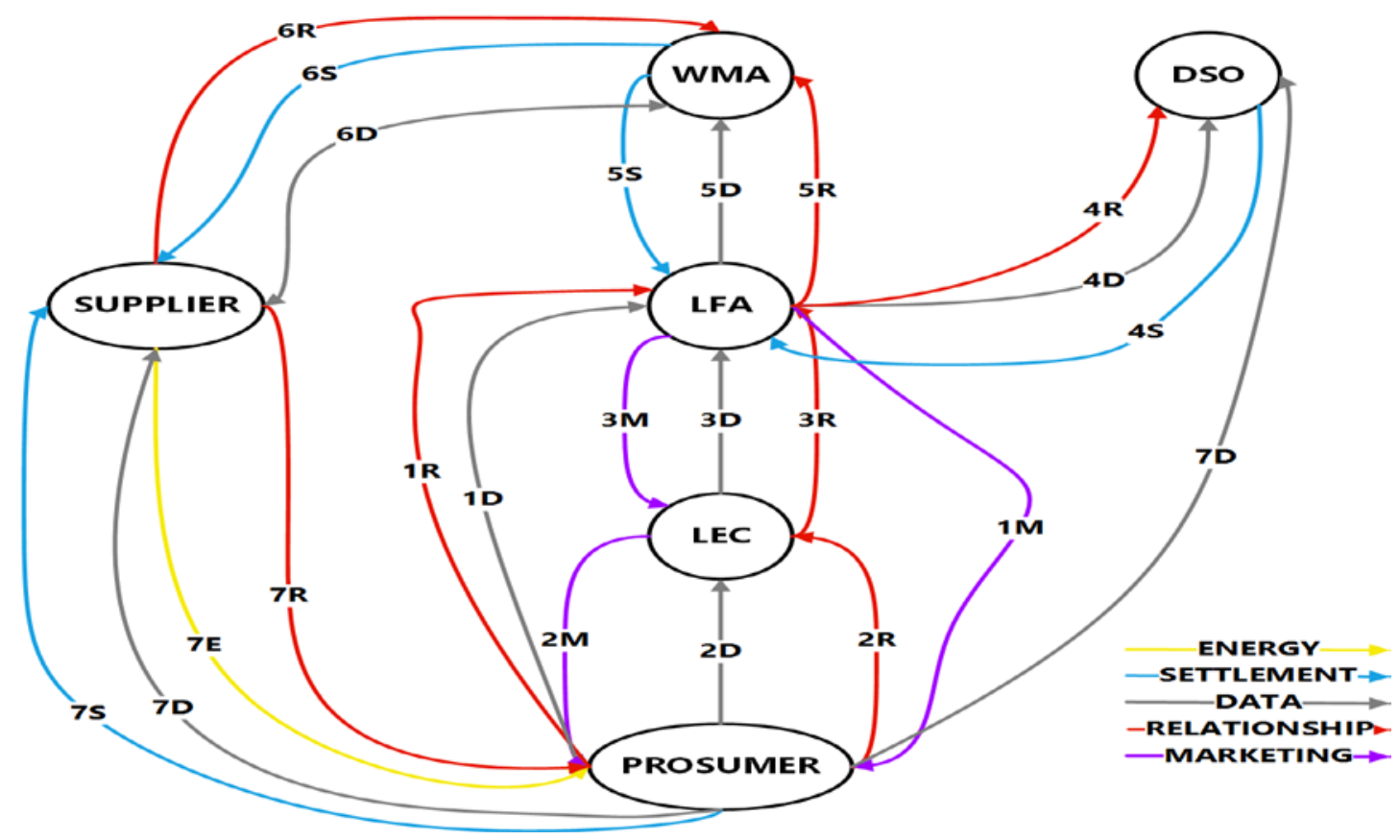

Figure 2. LFM and the LFA Relationships to other Energy Stakeholders 
Table II. Actor Interaction Flow in LFM

\begin{tabular}{|c|c|c|c|}
\hline Interacting Functions & Flow Type & Code & Flexibility Market Design \\
\hline Prosumer - LFA & Relationship & 1R & $\begin{array}{l}\text { Prosumers are part of an LEC because they are associated to the same } \\
\text { LFA by an individual contract. Prosumers have no knowledge of one } \\
\text { another and are free to choose the LFA that they prefer }\end{array}$ \\
\hline Prosumer - LFA & Data & 1D & Prosumer provides flexibility to the LFA \\
\hline LFA - Prosumer & Marketing & $1 \mathrm{M}$ & Advertising flexibility services and education of market \\
\hline Prosumer - LEC & Relationship & $2 \mathrm{R}$ & $\begin{array}{l}\text { Individuals sign up to a collective of local householders in order to } \\
\text { manage the flexibility commodity (sale \& settlement thereof). }\end{array}$ \\
\hline Prosumer - LEC & Data & 2D & $\begin{array}{l}\text { Individual Prosumers pool their combined flexibility into a marketable } \\
\text { commodity unit }\end{array}$ \\
\hline LEC - Prosumer & Marketing & $2 \mathrm{M}$ & Advertising flexibility services and education of market \\
\hline LEC-LFA & Data & 3D & The LFA buys the flexibility unit \\
\hline LEC-LFA & Relationship & $3 \mathrm{R}$ & The agreement governs the use of flexibility and settlement \\
\hline LFA- LEC & Marketing & $3 \mathrm{~m}$ & Advertising flexibility services and education of market \\
\hline LFA - DSO & Data & 4D & The LFA provides the flexibility unit to the DSO. \\
\hline LFA - DSO & Relationship & $4 \mathrm{R}$ & $\begin{array}{l}\text { Flexibility Service Contract. The agreement governs the use of } \\
\text { flexibility and settlement. }\end{array}$ \\
\hline DSO - LFA & Settlement & $4 \mathrm{~S}$ & $\begin{array}{l}\text { Buying Flexibility for congestion management, voltage control and } \\
\text { grid losses reduction. }\end{array}$ \\
\hline LFA - WMA & Data & $5 \mathrm{D}$ & $\begin{array}{l}\text { The LFA provides an internal portfolio optimization for the WMA and } \\
\text { occurs when the LFA receives a request from the WMA for the } \\
\text { provision of flexibility in aggregated form (as per classical centralised } \\
\text { management of flexibility). }\end{array}$ \\
\hline LFA - WMA & Relationship & $5 \mathrm{R}$ & $\begin{array}{l}\text { Contract will be in place which governs the use of flexibility and } \\
\text { settlement. }\end{array}$ \\
\hline WMA - LFA & Settlement & $5 \mathrm{~S}$ & Buying Flexibility to optimise its function (portfolio optimisation). \\
\hline WMA- Supplier & Data & 6D & Information exchange in order to forecast future portfolio consumption. \\
\hline Supplier - WMA & Relationship & 6R & Energy imbalance service contract. \\
\hline WMA- Supplier & Settlement & $6 \mathrm{~S}$ & $\begin{array}{l}\text { WMA pays compensation to the Supplier based on market-based } \\
\text { pricing of flexibility. }\end{array}$ \\
\hline Supplier-Prosumer & Energy & $7 \mathrm{E}$ & Supplier sells energy to Prosumer \\
\hline Prosumer - Supplier & Settlement & $7 \mathrm{~S}$ & $\begin{array}{l}\text { The Supplier agrees commercial conditions with its customers for the } \\
\text { supply and procurement of energy. }\end{array}$ \\
\hline Supplier - Prosumer & Relationship & $7 \mathrm{R}$ & Contractual relationship \\
\hline Prosumer - Supplier & Data & $7 \mathrm{D}$ & $\begin{array}{l}\text { Consumption Data. When flexibility contract is activated with the LFA, } \\
\text { the Prosumer should inform the Supplier. }\end{array}$ \\
\hline Prosumer-DSO & Data & $8 \mathrm{D}$ & $\begin{array}{l}\text { There is a data flow from the Prosumer to the DSO. Data is used to } \\
\text { calculate distribution charges. }\end{array}$ \\
\hline
\end{tabular}

As a business modelling methodology, Value Network Analysis (VNA) facilitated the visualization, analysis and insight into the business exchange flows and network relationships within the MPS (Ondrus, 2015). Figure 2 clearly shows that the LFM involves a complex networked web of stakeholder interactions to create value. Indeed, the multi-directional flows of energy and data evidenced in the value flow map clearly shows a more sophisticated marketplace and provide us with a contextual understanding of how a networked economy or multisided business platform could potentially materialize (Lynch et al., 2016c). As the LFA is serving multiple customers and facilitating the interactions those customers have with each other, the market model clearly matches any definition of a multi-sided business model that is bring together two or more distinct but interdependent groups of customers (Rochet and Tirole, 2003). 
In general, the LFM provides a mechanism for providers and buyers of products and services to interact and cocreate value that could not be created individually. For Lynch et al. (2016a) this is what makes the business model for the LFA multi-sided and complex in that it will be required to create, deliver, and capture value to multiple actors in the market. No current actor in the traditional model has a multi-sided nature to their business model so this will require the development of significantly different business model for whoever takes on the role of LFA. Revenue models within the MSP will be quite complex as the different trades along the value chain in the LFM are answered for and settled (Hagiu, 2014). The revenue flow will not only consist of funds as owed power for flexibility, reduced penalties, and other new forms of value capture enter into the business models of the actors in the LFM. There will also be multiple types of buyers and/or sellers and, in fact, a single party can be both a buyer and a seller. While customers are becoming more demanding, they also have much more to offer in return to power providers and other participants than just payment for energy consumed. Some of these new elements of reciprocal value are primarily operational in nature; demand response, load profile flexibility, and distributed power and storage allow for optimization of system performance and asset utilization. Others, such as information on energy consumption patterns, other consumer demographic and behavioural information, and access to personal connections/networks for marketing purposes, are the foundation for new revenue sources for companies able to effectively leverage the increased information and existing infrastructures.

\section{Conclusions}

Local flexibility is at the core of the emerging energy maket model landscape. Although emboynic, complex and challenging, this new market landscape holds new business and collaboration opportunities for all stakeholders and is the focus of our ongoing research endeavors. The emergence of prosumer communities changes the roles of the consumers in the local grid from having an individual passive relationship to an active participant in the value chain. Indeed, for the first time, end users will be empowered to participate directly in the electricity market and with greater choice. Consequently, businesses will have to become far more attuned to the needs of the prosumer, design new value propositions to maintain and attract their business and utilize the collaboration potential of their value chain network to provide a more responsive and interactive service model. In this paper, we proposed a LFM that involved local energy communities and where a local flexibility aggregator facilitates flexibility management between supploer, distribution system operators, and consumers/prosumers. While it presents new opportunities for incumbent energy providers to collaborate and develop new products, this recharacterization of the industry business platform brings with it additional constraints and challenges. There are obvious constraints to prosumer participation in that the amount of savings possible is going to have to be greater than the cost of investment to enable participation. Another constraint concerns privacy issues particularly in relation to data ownership. A particular challenge of MSPs is that a critical mass of prosumers will be required to create the network effect whereby all the other business actors around the LFA will come on board, which is often referred to the chicken and eegg problem. Indeed, inorder to ignite the LFM, the LFA will have to devote much attention to designing innovative business strategies to get on-board as many early adopters as possible in order to drive this network effect.

\section{References}

Ala-Juusela, M.; Short, M.; Shvadron, U. 2014. Tools to support sustainable entrepreneurship in energy positive neighbourhoods, Entrepreneurship and Sustainability Issues 2(2): 49-59. DOI: http://dx.doi.org/10.9770/jesi.2014.2.2(1)

BNE. (2015). Decentralized Flexibility. Online. Available on the internet: http://www.bneonline.de/de/system/files/files/attachment/20150122_bne_De-Flex-Market.pdf 
Dupont, B., Vingerhoets, P., Tant, P., Vanthournout, K., Cardinaels, W., De Rybel, Peeters, E. and Belmans, R. (2012). LINEAR breakthrough project: Large-scale implementation of smart grid technologies in distribution grids. Innovative Smart Grid Technologies (ISGT Europe). Berlin, Germany: IEEE PES.

EC Europa. (2015). Regulatory Recommendations for the Deployment of Flexibility. EG3 EU Smartgrid Task Force. Available on the internet: http://ec.europa.eu/energy/sites/ener/files/documents/EG3\%20Final\%20-\%20January\%202015.pdf

European Commission, (2015a) “Delivering a new deal for energy consumers,” COM(2015) 339, EC, Brussels, Belgium.

European Commission, (2015b), “Launching the public consultation process on a new energy market design,” COM(2015) 340, EC, Brussels, Belgium.

EURELECTRIC. (2011). Views on Demand-Side Participation: Involving Customers, Improving Markets, Enhancing Network Operation Task Force Smart Grids, Flexible Loads and Storage. EURELECTRIC. Available on the internet: http://www.eurelectric.org/media/61240/dsp_report_0810-02_simple_page_final-2011-030-0638-01-e.pdf

EURELECTRIC. 2014 Flexibility and Aggregation, Brussels. Available http://www.eurelectric.org/media/115877/tf_balagr_report_final_je_as-2014-030-0026-01-e.pdf

Hagiu, A. 2014. Strategic decisions for multisided platforms. MIT Sloan Management Review, 55(2), p.71.

Hagui, A. 2015. Multi Sided Markets. Harvard Business Review,, Working Paper, 15037.

IEA-RETD. 2014. Residential Prosumer - Drivers and Policy Options (Re-Prosumers). Available on the internet: http://iea-retd.org/wpcontent/uploads/2014/06/RE-PROSUMERS_IEA-RETD_2014.pdf

Lennard, Z., Messervey, T., Espeche, J. Genesi, C et al., 2015. Use Cases and Business Models Vision I: High-level requirements, use cases, and business orientations. Deliverable D1.6, Mas2tering EU Project.

Lynch, P., Power, J., Hickey, R. Kelly, D, Messervey, T., Espeche, J., and Oualmakran, Y. 2016a, “Maximising Value for Local Flexibility Management in Low Voltage Distribution Networks" in IEEE CASE: Collective and Adaptive Smart Energy management in districts and neighbourhoods. September 12-15. Trento, Italy

Lynch, P., Power, P., Hickey, R., Kelly, D., Messervey, T 2016b, Re-Imagining Business Model Opportunities in the Utility Sector: Aligning Business Collaboration Opportunities to SmartGrid Technology Developments and Architecture. Irish Academy of Manaagement Conference, University College Dublin, Aug 31-Sept 2

Lynch, P., Messervey, T., Espeche, J., Lennard, Z., et al., 2016c. Business Strategies and Collaboration Opportunities. Deliverable D1.5, Mas2tering EU Project.

Mourshed, M., Robert, S., Ranalli, A., Messervey, T., Reforgiato, D., Contreau, Becue, A., Quinn, K., Rezgui, Y. And Lennard, Z. 201). Smart grid futures: Perspectives on the integration of energy and ICT services. Energy Procedia, 75, 1132-1137.

Ondrus, J. A. 2015. The impact of openness on the market potential of multi-sided platforms: a case study of mobile payment platforms . Journal of Information Technology , 30, 260-275.

Peppard, J., \& Rylander, A. 2006. From Value Chain to Value Network: Insights for Mobile Operators. European Management Journal, 24(2).

Rathnayaka, A., Potdar, V., Hussain, O., \& Dillon, T. 2011. Identifying prosumer's energy sharing behaviours for forming optimal prosumer-communities. Cloud and Service Computing (CSC) (lpp. 196-206). IEEE.

Richter, M. 2012. Utilities’ Business Models for Reneable Energy: A Review. Renewable and Sustainable Energy Reviews, 16, 5, 24832493. http://dx.doi.org/10.10.16/J.RSER.2012.01.072 
The International Journal

ENTREPRENEURSHIP AND SUSTAINABILITY ISSUES

ISSN 2345-0282 (online) http://jssidoi.org/jesi/ 2017 Volume 4 Number 3 (March)

Rochet, J., \& Tirole, J. (2003). Platform Competition in Two-Sided Markets. Journal of the European Economic Association, 1, $990-1029$.

Steinheimer, M., \& Ulrich T, Uhring,. P. 2012. "Energy communities in Smart Markets for optimisation of peer-to-peer interconnected Smart Homes. CSNDSP.

Valocchi, M., Juliano, J., Schurr, A., 2010. Switching Perspective: Creating New Business Models for a Changing World of Energy. IBM Institute for Business Value, Executive Report. Available on the internet: http://www935.ibm.com/services/multimedia/Switching_perspectives.pdf

Valocchi, M., Juliano, J., \& Schurr, A. 2012. Evolution: Smart Grid Technology Requires Creating New Business Models. Reinventing Energy, 62-67.

Wainsteina, M., \& Bumpus, A. 2016. Business models as drivers of the low carbon power system transition: a multi-level perspective. Journal of Cleaner Production, 126, 572-585.

\section{Aknowledgements}

This research was supported by the project Mas'tering (www.mas2tering.com), which has received funding from the European Union's FP7 research and innovation programme under the grant agreement No 619682.

The article reflects the views only of the authors, and the Commission cannot be held responsible for any use which may be made of the information contained therein. The information in this document is provided as is and no guarantee or warranty is given that the information is fit for any particular purpose. The user thereof uses the information at its sole risk and liability

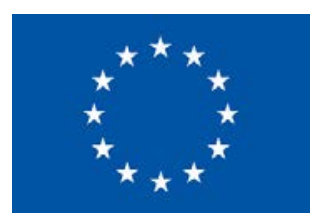

\section{Authors}

Patrick J. LYNCH is the director of RIKON-WIT, a business innovation research centre located in Waterford Institute of Technology in Irekand. He has published extensively on business models and networked innovation in top-tier journals and peer-reviewed conferences and has received numerous accolades including the 2013 Emerald Global Literati Prize for Excellence. He has amassed considerable industry, consultancy and applied innovation research experience in process optimisiation, business \& market modelling \& digital transformation. Patrick manages a team of 40 plus researchers and business strategirss and is the principal investigator on over 450 innovation and research projects that are recognised for making real transformational change in business and re-imaging how companies can identify tactical business opportunities to grow business volume and develop breakthrough strategies and innovative business models to seize those opportunities and transform their organization to execute the new growth strategy. Of particular interest to Patrick is the new data-driven business models that are transforming the energy supply chain and re-defining the role of the stakeholders in these new networked market models.

ORCID ID: 0000-0002-5406-3846 


\section{ENTREPRENEURSHI The International Journal}

The International Journal
TAINABILITY ISSUES

ISSN 2345-0282 (online) http://jssidoi.org/jesi/ 2017 Volume 4 Number 3 (March)

Richard HICKEY is a Business Development Strategist in RIKON-WIT and works closely with organisations to find solutions to their business model challenges by developing and applying various research methodologies and helping them achieve their research goals. ORCID ID: 0000-0002-4521-8295

Jamie POWER is the EU Research Programme Manager for RIKON and leads the development of RIKON's national and European project, collaboration and research funding activities in addition to coordinating the Group's knowledge transfer, publication and dissemination agendas. Jamie's research interest includes the evolution of business models and the interaction dynamics of stakeholders in networked business and market models.

ORCID ID: 0000-0003-1550-7982

Thomas B. MESSERVEY is the Chief Executive Officer, R2M Solution and has over 20 years of engineering experience spanning military service in the US Army Corps of Engineers, Industrial Experience with the Italian Engineering Company D’Appolonia, teaching excellence at the United States Military Academy at West Point, and Coaching services as the EU Facilitator for the Intelligent Manufacturing Systems program. He serves as an expert for the European Commission in textiles, manufacturing, and energy efficiency. His research interests focus on using sensor data to make better engineering decisions across design, assessment, maintenance, inspections, and energy management to include machine learning. He is passionate about linking international research efforts to boost competitiveness. He is a member of the International Association of Bridge Maintenance and Safety (IABMAS), the International Association of Life Cycle Civil Engineering (IALCCE), and a technical reviewer for the International Journal of Safety and Security Engineering and the Journal of Structure and Infrastructure Engineering. He is an organizer of the annual International Electronic Conference on Sensors and Applications.

ORCID ID: 0000-0003-1746-9975

Copyright (c) 2016 by author(s) and VsI Entrepreneurship and Sustainability Center This work is licensed under the Creative Commons Attribution International License (CC BY). http://creativecommons.org/licenses/by/4.0/

(c) (i) Open Access 